\title{
FORECASTING RETURN PRODUCTS IN AN INTEGRATED FORWARD/REVERSE SUPPLY CHAIN UTILIZING AN ANFIS
}

\author{
D. Thresh KUMAR *, HAMEd SOLEIMANI **, GOVINDAN KANNAN *** \\ * Department of Mechanical Engineering \\ PTR College of Engineering and Technology, Thangapandiyan Nagar, Austinpatti (Po) \\ Madurai, 625008, Tamil Nadu, India \\ ** Faculty of Industrial and Mechanical Engineering \\ Qazvin Branch, Islamic Azad University (IAU), Barajin, Nokhbegan Boulevard, Qazvin, Iran \\ *** Department of Business and Economics \\ University of Southern Denmark, Campusvej 55, Odense M, 5230, Denmark \\ e-mail: gov@sam.sdu.dk
}

\begin{abstract}
Interests in Closed-Loop Supply Chain (CLSC) issues are growing day by day within the academia, companies, and customers. Many papers discuss profitability or cost reduction impacts of remanufacturing, but a very important point is almost missing. Indeed, there is no guarantee about the amounts of return products even if we know a lot about demands of first products. This uncertainty is due to reasons such as companies' capabilities in collecting End-of-Life (EOL) products, customers' interests in returning (and current incentives), and other independent collectors. The aim of this paper is to deal with the important gap of the uncertainties of return products. Therefore, we discuss the forecasting method of return products which have their own open-loop supply chain. We develop an integrated two-phase methodology to cope with the closed-loop supply chain design and planning problem. In the first phase, an Adaptive Network Based Fuzzy Inference System (ANFIS) is presented to handle the uncertainties of the amounts of return product and to determine the forecasted return rates. In the second phase, and based on the results of the first one, the proposed multi-echelon, multi-product, multi-period, closed-loop supply chain network is optimized. The second-phase optimization is undertaken based on using general exact solvers in order to achieve the global optimum. Finally, the performance of the proposed forecasting method is evaluated in 25 periods using a numerical example, which contains a pattern in the returning of products. The results reveal acceptable performance of the proposed two-phase optimization method. Based on them, such forecasting approaches can be applied to real-case CLSC problems in order to achieve more reliable design and planning of the network.
\end{abstract}

Keywords: artificial neural network, adaptive network based fuzzy inference system, closed-loop supply chain, forecasting methods, fuzzy neural network.

\section{Introduction}

Legal, economical, and social factors force companies to cope with their end-of-life products. Although the classical supply chain contains the value chain from suppliers to customers (called the forward supply chain), to be able to sustain, it is needed to deal with the products used, and close the loop of the classical supply chain by a reverse supply chain. Today, dealing with the design and planning problem of a closed-loop supply chain is an unavoidable but difficult issue. For real-size instances, it is an NP-hard problem (Krarup and Pruzan, 1983; Schrijver, 2004), and we do not know the quality of the solutions. On the other hand, to construct a profitable reverse supply chain amounts of return play the main role.

However, we cannot be sure about the rate of return of total demands which enter the reverse supply chain. Reviewing the closed-loop supply chain literature, we can find numerous valuable papers on designing and planning issues of a supply chain. Meanwhile, if we do not have precise information on return amounts, we cannot construct a reliable and profitable closed-loop supply 
chain. Therefore, studying the forecasting methods of the amounts of return products is a vital issue at a preliminary stage of designing and planning a closed-loop supply chain. Generally, the uncertainties of return products are due to three main reasons: limited capabilities of collecting networks of companies, customers' lack of awareness (or poor incentive methods) of preventing them to dispose EOL products directly, and other independent collection parties. These considerations clarify the very important role of reliable forecasting methods of return products in a closed-loop supply chain. In this paper, we try to cover the above-mentioned vital gap.

Based on the uncertain and fluctuated markets, forecasting methodologies are widely used in different fields of science directly or indirectly. Artificial neural network methodologies and their combinations like fuzzy neural networks are some of the well-known methods of forecasting, which are successfully utilized and evaluated in various fields including supply chain (see the works of Efendigil et al. (2009) (in fuzzy), Brdyś et al. (2009) (in stock exchange), Sumi et al. (2012) (in rainfall forecasting), Ozkr and Balgil (2013) (in the fuzzy approach), Georgiadis (2013) (in system dynamics), and Soleimani et al. (2014) (in risk management)). Indeed, the ability of the self-learning of the neural network-based methodologies makes them powerful techniques of forecasting. Thus, we develop this method in the important problem of closed-loop supply chain design and planning regarding uncertain products return.

In this paper, a very important issue of forecasting return products in a closed-loop supply chain is considered. To the best of our knowledge, despite the vital role of the amounts of return products in reverse logistics profitability, this issue remains an important gap. Thus, in order to optimize the problem of designing a closed-loop supply chain, a two-phase methodology is developed. In the first phase, amounts of return products are forecasted utilizing an ANFIS. Then, in the second phase, and based on the results of the previous phase, the CLSC problem is optimized. Indeed, we try to fill this gap by exploiting an artificial neural fuzzy inferences system. We develop the ANFIS methodology and evaluate its performance within a numerical analysis of 25 periods in multi-echelon, multi-product, multi-period closed-loop supply chain design and planning. Finally, the optimal location and allocation decision variables are obtained in the second phase.

The remainder of the paper is arranged as follows. A literature review is presented in Section 2. Section 3 is devoted to the conceptual and mathematical representation of the proposed model of closed-loop supply chain design and planning. Comprehensive illustrations of the proposed two-stage solution methodology are discussed in Section 4. Section 5 is dedicated to computational analysis of the proposed methodology to evaluate the performance of the proposed ANFIS and to solve the given model. Finally, Section 6 is to clarify the conclusions and future extensions of the current research.

\section{Literature review}

Neural network based forecasting methods and their combinations are widely used in numerous problems of various fields. Neural network methods, neuro-fuzzy techniques, and adaptive network based fuzzy inference systems are some of these well-known combinations. Indeed, in different research attempts, authors could utilize and present different combinations of neural network forecasting methodologies as acceptable, well behaved and reliable forecasting methods.

Table 1 illustrates an overview of the utilization of neural network-based forecasting methodologies in selected real problems, which can present the applicability characteristics of these methods in different fields. Reviewing Table 1 will clarify the vast areas in which the ANFIS and similar methods have been successfully employed. Meanwhile, the ANFIS is the most applicable and well-behaved methodology among the whole neural network based forecasting methodologies. Further, considering the popular fuzzy inference system is one of the other strengths of the ANFIS. Finally, we exploit the benefits of the ANFIS in the proposed CLSC location-allocation problem.

On the other hand, design and planning an integrated closed-loop supply chain is an important but NP-hard problem. The main parameter to achieve a profitable reverse supply chain is the amount of return products. In real markets, we have little information of the amounts of the return products so it is necessary to analyze these amounts before optimizing the main problem. There are few works which have considered this important gap in a closed-loop supply chain.

Since the returning of products is a vital issue, there is some conceptual research, which attempts to discuss the influential factors of return products. Although it does not consider the quantitative analysis of return, it could clarify its impacts on the profitability of reverse channels of a supply chain. Guide and Van Wassenhove (2001) discussed the value-creating characteristics of reuse activities. They attempted to show how product return management influences the overall profitability of such activities. Finally, they debated on how operational issues are strongly affected by the approach used to manage product returns. Generally, they presented a fundamentally new approach to the economics and operations of reuse activities. Srivastava (2006), concentrating a bit more on the forecasting issues, presented a framework to manage product returns for a reverse supply chain. The author focused on estimating of 
the returns for selected categories of products in the Indian context, developing a conceptual integrated framework and utilizing product ownership data, average life cycle of products, past sales, forecasted demand, and likely the impact of environmental policy measures on estimating return flows. These papers clarify the necessities of achieving a reliable estimation of return.

We can also find some papers related to the forecasting of return products. Toktay et al. (2003) reviewed data-driven methods for forecasting return flows that exploit the fact that future returns are a function of

Table 1. Overview of neural network-based forecasting methodologies.

\begin{tabular}{|c|c|}
\hline Paper & Problem \\
\hline Efendigil et al. (2009) & $\begin{array}{l}\text { Supply chain } \\
\text { management }\end{array}$ \\
\hline Yun et al. (2008) & $\begin{array}{c}\text { Price of } \\
\text { electricity }\end{array}$ \\
\hline Chang and Chang (2006) & $\begin{array}{l}\text { Water resources } \\
\text { management }\end{array}$ \\
\hline Jun Li and Xiong (2005) & $\begin{array}{c}\text { Yield } \\
\text { optimization }\end{array}$ \\
\hline Chen et al. (2006) & $\begin{array}{c}\text { Crisis } \\
\text { management }\end{array}$ \\
\hline Liao et al. (2001) & $\begin{array}{c}\text { Human resources } \\
\text { management }\end{array}$ \\
\hline Sfetsos (2000) & $\begin{array}{c}\text { Power generating } \\
\text { sources management }\end{array}$ \\
\hline Paper & Forecasting parameter \\
\hline Efendigil et al. (2009) & $\begin{array}{c}\text { Demand } \\
\text { forecasting }\end{array}$ \\
\hline Yun et al. (2008) & $\begin{array}{c}\text { Load } \\
\text { forecasting }\end{array}$ \\
\hline Chang and Chang (2006) & $\begin{array}{l}\text { Water level } \\
\text { forecasting }\end{array}$ \\
\hline Jun Li and Xiong (2005) & $\begin{array}{l}\text { Forecast indices and } \\
\text { prices of stock market }\end{array}$ \\
\hline Chen et al. (2006) & $\begin{array}{c}\text { Flood } \\
\text { forecasting }\end{array}$ \\
\hline Liao et al. (2001) & $\begin{array}{l}\text { Forecasting demand } \\
\text { of teachers }\end{array}$ \\
\hline Sfetsos (2000) & $\begin{array}{l}\text { Mean hourly wind } \\
\text { speed forecasting }\end{array}$ \\
\hline Paper & Methodology \\
\hline Efendigil et al. (2009) & $\begin{array}{c}\text { Artificial neural } \\
\text { networks and the ANFIS }\end{array}$ \\
\hline Yun et al. (2008) & ANFIS \\
\hline Chang and Chang (2006) & ANFIS \\
\hline Jun Li and Xiong (2005) & $\begin{array}{c}\text { Fuzzy neural } \\
\text { network }\end{array}$ \\
\hline Chen et al. (2006) & ANFIS \\
\hline Liao et al. (2001) & ANFIS \\
\hline Sfetsos (2000) & $\begin{array}{l}\text { ANFIS and neural } \\
\text { logic networks }\end{array}$ \\
\hline
\end{tabular}

past sales. They presented a forecasting model based on the given past sales volumes, which can estimate the return probability and the return delay distribution. They compared the performance of their forecasting methods in an inventory management issue. Temur and Bolat (2012) considered a reverse logistic network design problem, and proposed a two-section methodology, which first utilized an intelligent system development to forecast return amounts and then tried to optimize a mixed integer linear programming (MILP) location-allocation problem of reverse logistic network design. They just consider a reverse logistic network in a single period and they utilize an artificial neural network method as their forecasting methodology.

Marx-Gomez et al. (2002) worked on the forecasting problem, but just on the recycling part of a reverse logistic. In their simulation study, they presented a forecasting method to provide prognoses for return values (amount and time) of scrapped products for recycling. The proposed forecasting method was a fuzzy inference system for the forecasting of the return in a determined planning period and a neuro-fuzzy system for the forecasting of return values with respect to time. $\mathrm{Xu}$ and Fan (2009) also considered a reverse logistic network in which they proposed a new model based on the wave function to forecast the amount of returned products of reverse logistics. For the periodic characteristics of the wastes, they rationally developed such a wave function.

Chittamvanich and Ryan (2011) dealt with a single-period model for the capacity management problem to determine the optimal level of remanufacturing capacity. They jointly analyzed forecasting and capacity management of returned products to evaluate the benefit of information obtained from early returns. Using confidence intervals by the maximum likelihood method, they could estimate the distribution parameters of return time. Finally, a summary of the literature survey is illustrated in Table 2.

Reviewing the presented literature and its summary in Table 2, the contribution of this paper is distinguished in terms of model and forecasting methodology. In this paper, we consider an integrated closed-loop supply chain design and planning problem and we use the advance method of the ANFIS for forecasting returns. Indeed, a two-phase solution methodology is proposed and utilized in this paper. Before presenting the mentioned solution methodology, the complete model is illustrated in the next section.

\section{Model description and formulation}

In this study, multi-product, multi-period, and multi-echelon closed-loop supply chain design and planning are constructed based on the work of Soleimani et al. (2013) with the following assumptions: 
Table 2. Summary of the literature survey.

\begin{tabular}{|c|c|c|}
\hline Paper & Problem & $\begin{array}{c}\text { Model } \\
\text { characteristics }\end{array}$ \\
\hline $\begin{array}{c}\text { Guide and Van } \\
\text { Wassenhove (2001) }\end{array}$ & $\begin{array}{l}\text { Reverse } \\
\text { logistics }\end{array}$ & Conceptual \\
\hline $\begin{array}{c}\text { Srivastava and } \\
\text { Srivastava (2006) }\end{array}$ & $\begin{array}{l}\text { Reverse } \\
\text { logistics }\end{array}$ & Conceptual \\
\hline $\begin{array}{l}\text { Toktay et } \\
\text { al. }(2003)\end{array}$ & $\begin{array}{l}\text { Reverse } \\
\text { logistics }\end{array}$ & $\begin{array}{c}\text { Inventory } \\
\text { management }\end{array}$ \\
\hline $\begin{array}{c}\text { Temur and } \\
\text { Bolat (2012) }\end{array}$ & $\begin{array}{l}\text { Reverse } \\
\text { logistics }\end{array}$ & $\begin{array}{c}\text { Single period, } \\
\text { location-allocation }\end{array}$ \\
\hline $\begin{array}{l}\text { Marx-Gomez et } \\
\text { al. (2001) }\end{array}$ & $\begin{array}{l}\text { Reverse } \\
\text { logistics }\end{array}$ & $\begin{array}{l}\text { Recycling } \\
\text { planning }\end{array}$ \\
\hline $\begin{array}{c}\text { Xu and } \\
\text { Tijun (2009) }\end{array}$ & $\begin{array}{l}\text { Reverse } \\
\text { logistics }\end{array}$ & $\begin{array}{c}\text { Forecasting } \\
\text { model }\end{array}$ \\
\hline $\begin{array}{l}\text { Chittamvanich } \\
\text { and Ryan (2011) }\end{array}$ & $\begin{array}{l}\text { Reverse } \\
\text { logistics }\end{array}$ & $\begin{array}{c}\text { Remanufacturing } \\
\text { capacity } \\
\text { management }\end{array}$ \\
\hline $\begin{array}{l}\text { Our presented } \\
\text { methodology }\end{array}$ & Closed-loop & $\begin{array}{c}\text { Multi-period, } \\
\text { multi-product, } \\
\text { location-allocation }\end{array}$ \\
\hline Paper & $\begin{array}{c}\text { Forecasting } \\
\text { parameter }\end{array}$ & Methodology \\
\hline $\begin{array}{c}\text { Guide and Van } \\
\text { Wassenhove (2001) }\end{array}$ & - & - \\
\hline $\begin{array}{c}\text { Srivastava and } \\
\text { Srivastava (2006) }\end{array}$ & - & - \\
\hline $\begin{array}{c}\text { Toktay } \text { et } \\
\text { al. }(2003)\end{array}$ & $\begin{array}{l}\text { Return } \\
\text { delay }\end{array}$ & $\begin{array}{l}\text { Estimate the } \\
\text { return probability }\end{array}$ \\
\hline $\begin{array}{c}\text { Temur and } \\
\text { Bolat (2012) }\end{array}$ & $\begin{array}{c}\text { Return } \\
\text { amounts }\end{array}$ & $\begin{array}{c}\text { Artificial } \\
\text { neural network }\end{array}$ \\
\hline $\begin{array}{l}\text { Marx-Gomez et } \\
\text { al. (2001) }\end{array}$ & $\begin{array}{l}\text { Return period } \\
\text { Return value }\end{array}$ & $\begin{array}{l}\text { Fuzzy inference } \\
\text { system and neuro- } \\
\text { fuzzy system }\end{array}$ \\
\hline $\begin{array}{c}\text { Xu and } \\
\text { Tijun (2009) }\end{array}$ & $\begin{array}{l}\text { Return } \\
\text { amounts }\end{array}$ & $\begin{array}{c}\text { Wave } \\
\text { function }\end{array}$ \\
\hline $\begin{array}{c}\text { Chittamvanich } \\
\text { and Ryan (2011) }\end{array}$ & $\begin{array}{c}\text { Return } \\
\text { amounts }\end{array}$ & $\begin{array}{l}\text { Max likelihood } \\
\text { estimation }\end{array}$ \\
\hline $\begin{array}{l}\text { Our presented } \\
\text { methodology }\end{array}$ & $\begin{array}{c}\text { Return } \\
\text { amounts }\end{array}$ & ANFIS \\
\hline
\end{tabular}

- The amounts of return products are not predetermined and should be forecasted.

- The model is multi-echelon, multi-period, and multi-product. It consists of these echelons: suppliers, manufacturers, warehouses, distributors, retailers (customers), disassembly centers (collection centers), redistributors, disposal centers, and second customers.

- The potential locations, capacities of all facilities and all cost parameters are predetermined.

- All costs like shortage costs, holding costs, etc. are dependant on the products so they are not fixed for all products.
The complete formulation of the MILP model is presented as follows:

Sets:

$S$ : Potential number of suppliers, indexed by $s$.

$F$ : Potential number of manufacturers, indexed by $f$.

$W$ : Potential number of warehouses, indexed by $w$.

$D$ : Potential number of distributors, indexed by $d$.

$C$ : Potential number of the first customers (retailers), indexed by $c$.

$A$ : Potential number of disassembly centers, indexed by $a$.

$R$ : Potential number of redistributors, indexed by $r$.

$P$ : Potential number of disposal locations, indexed by $p$.

$K$ : Potential number of second customers, indexed by $k$.

$U$ : Number of products, indexed by $u$.

$T$ : Number of periods, indexed by $t$.

\section{Main indices:}

$i$ : Index which regards any entity that can belong to any sets: $S, F, W, D, C, A, R, P, K, U, T$.

$j$ : Index which regards to any entity that can belong to any sets: $S, F, W, D, C, A, R, P, K, U, T$.

\section{Parameters:}

$S^{\prime}$ : Maximum number of suppliers.

$F^{\prime}$ : Maximum number of manufacturers.

$W^{\prime}$ : Maximum number of warehouses.

$D^{\prime}$ : Maximum number of distributors.

$A^{\prime}$ : Maximum number of disassembly centers.

$R^{\prime}$ : Maximum number of redistributors.

$P^{\prime}$ : Maximum number of disposal locations.

$M$ : Sufficiently large constant.

$D_{\text {cut }}$ : Demand of product $u$ of first the customer $c$ in period $t$.

$D_{k u t}$ : Demand of product $u$ of the second customer $k$ in period $t$.

$P_{\text {cut }}$ : Unit price of product $u$ at the first customer $c$ in period $t$.

$P U_{c u t}$ : Purchasing cost of product $u$ at the first customer $c$ in period $t$.

$P_{k u t}$ : Unit price of product $u$ at the second customer $k$ in period $t$,

$F_{i}$ : The fixed cost of the opening location $i$.

$D S_{i j}$ : Distance between any two locations $i$ and $j$.

$S C_{\text {sut }}$ : Capacity of supplier $s$ of product $u$ in period $t$.

$S R C_{\text {sut }}$ : Recycling capacity of supplier $s$ of product $u$ in period $t$.

$F C_{f u t}$ : Manufacturing capacity of manufacturer $f$ of product $u$ in period $t$.

$R F C_{f u t}$ : Remanufacturing capacity of manufacturer $f$ of product $u$ in period $t$.

$W C_{w u t}$ : Warehouse capacity in hours of warehouse $w$ of product $u$ in period $t$.

$D C_{d u t}$ : Capacity of distributor $d$ of product $u$ in period $t$. 
$A C_{a u t}$ : Capacity of disassembly $a$ of product $u$ in period $t$.

$R D C_{\text {rut }}$ : Capacity of redistributor $r$ of product $u$ in period $t$.

$P C_{\text {put }}$ : Capacity of disposal center $p$ of product $u$ in period $t$.

$M T_{\text {sut }}$ : Material cost of product $u$ per unit supplied by supplier $s$ in period $t$.

$R T_{\text {sut }}$ : Recycling cost of product $u$ per unit recycled by supplier $s$ in period $t$.

$F T_{f u t}$ : Manufacturing cost of product $u$ per unit manufactured by manufacturer $f$ in period $t$.

$R F T_{\text {fut }}$ : Remanufacturing cost of product $u$ per unit by manufacturer $f$ in period $t$.

$D A T_{\text {aut }}$ : Disassembly cost of product $u$ per unit by disassembly center $a$ in period $t$.

$R P T_{\text {aut }}$ : Repairing cost of product $u$ per unit repaired by disassembly location $a$ in period $t$.

$P T_{\text {aut }}$ : Disposal cost of product $u$ per unit disposed by disposal location $p$ in period $t$.

$N M T_{f u t}$ : Non-utilized manufacturing capacity cost of product $u$ of manufacturer $f$ in period $t$.

$N R M T_{f u t}$ : Non-utilized remanufacturing cost of product $u$ of manufacturer $f$ in period $t$.

$S T_{u t}$ : Shortage cost of product $u$ per unit in period $t$,

$F h_{f u}$ : Manufacturing time of product $u$ per unit at manufacturer $f$.

$R F h_{f u}$ : Remanufacturing time of product $u$ per unit at manufacturer $f$.

$R T_{\text {sut }}$ : Recycling cost of supplier $s$ of product $u$ in period $t$.

$W H T_{w u t}$ : Holding cost of product $u$ per unit at the warehouse $w$ in period $t$.

$D H T_{d u t}$ : Holding cost of product $u$ per unit at distributor store $d$ store in period $t$.

$B_{s u}, B_{f u}, B_{d u}, B_{a u} B_{r u} B_{w u} B_{c u}$ : Batch size of product $u$ from supplier $s$, manufacturer $f$, distributor $d$, disassembly $a$, redistributor $r$, warehouse $w$ and customer $c$ respectively.

$T R T_{u t}$ : Transportation cost of product $u$ per unit per kilometer in period $t$.

$R R_{u t}$ : Return ratio of product $u$ at the first customers in period $t$.

$R_{c}$ : Recycling ratio.

$R_{m}$ : Remanufacturing ratio.

$R_{r}$ : Repairing ratio.

$R_{p}$ : Disposal ratio.

\section{Decision variables:}

$L_{i}$ : Binary variable equals 1 if location $i$ is activated and 0 otherwise.

$T L_{i j}$ : Binary variable which is equal to 1 if a transportation link is established between node $i$ and node $j$ in any period and 0 otherwise.
$Q_{i j u t}$ : Flows of product $u$ batches from node (entity) $i$ to the node (entity) $j$ in period $t$.

$R_{w u t}$ : The residual inventory of product $u$ at warehouse $w$ in period $t$.

$R_{d u t}$ : The residual inventory of product $u$ at distributor $d$ in period $t$.

3.1. Objective function. We consider profit value as the objective function of the model. Hence, all sales and costs should be calculated:

\section{Total sales:}

\section{Sales of all products:}

First products sales (flows from distributors, manufacturers and warehouses):

$$
\begin{aligned}
& \sum_{d \in D} \sum_{c \in C} \sum_{u \in U} \sum_{t \in T} Q_{d c u t} B_{d u} P_{c u t} \\
& +\sum_{f \in D} \sum_{c \in C} \sum_{u \in U} \sum_{t \in T} Q_{f c u t} B_{f u} P_{c u t} \\
& +\sum_{w \in D} \sum_{c \in C} \sum_{u \in U} \sum_{t \in T} Q_{w c u t} B_{w u} P_{c u t} .
\end{aligned}
$$

Second products sales (flows from redistributors, manufacturers and warehouses):

$$
\begin{aligned}
& \sum_{r \in R} \sum_{k \in K} \sum_{u \in U} \sum_{t \in T} Q_{r k u t} B_{r u} P_{k u t} \\
& +\sum_{f \in D} \sum_{k \in K} \sum_{u \in U} \sum_{t \in T} Q_{f k u t} B_{f u} P_{c u t} \\
& +\sum_{w \in D} \sum_{k \in K} \sum_{u \in U} \sum_{t \in T} Q_{w k u t} B_{w u} P_{c u t} .
\end{aligned}
$$

\section{Total costs:}

Total costs $=$ fixed costs + material costs + manufacturing costs + non-utilized capacity costs + shortage costs + purchasing costs + disassembly costs + recycling costs + remanufacturing costs + repairing costs + disposal costs + transportation costs + inventory holding costs.

\section{Fixed costs:}

$$
\begin{aligned}
& \sum_{s \in S} F_{s} L_{s}+\sum_{f \in F} F_{f} L_{f}+\sum_{d \in D} F_{d} L_{d} \\
& +\sum_{a \in A} F_{a} L_{a}+\sum_{r \in R} F_{r} L_{r}+\sum_{p \in P} F_{p} L_{p}+\sum_{w \in W} F_{w} L_{w} .
\end{aligned}
$$

\section{Material costs:}

$$
\begin{aligned}
& \sum_{s \in S} \sum_{f \in F} \sum_{u \in U} \sum_{t \in T} Q_{s f u t} B_{s u} M c_{s u t} \\
& -\sum_{a \in A} \sum_{s \in S} \sum_{u \in U} \sum_{t \in T} Q_{a s u t} B_{a u}\left(M c_{s u t}-R c_{s u t}\right) .
\end{aligned}
$$

\section{Manufacturing costs:}

$$
\begin{aligned}
& \sum_{f \in F} \sum_{d \in D} \sum_{u \in U} \sum_{t \in T} Q_{f d u t} B_{f u} F c_{f u t} \\
& +\sum_{f \in F} \sum_{w \in W} \sum_{u \in U} \sum_{t \in T} Q_{f w u t} B_{f u} F c_{f u t} \\
& +\sum_{f \in F} \sum_{c \in C} \sum_{u \in U} \sum_{t \in T} Q_{f c u t} B_{f u} F c_{f u t} \\
& +\sum_{f \in F} \sum_{k \in K} \sum_{u \in U} \sum_{t \in T} Q_{f k u t} B_{f u} F c_{f u t} .
\end{aligned}
$$


Non-utilized capacity cost (for manufacturers):

$$
\begin{aligned}
& \sum_{f \in F}\left(\sum _ { u \in U } \left(\sum _ { t \in T } \left(\left(F C_{f u t} / F h_{f u}\right) L_{f}\right.\right.\right. \\
& -\sum_{d \in D}\left(Q_{f d u t} B_{f u}\right)-\sum_{w \in W}\left(Q_{f w u t} B_{f u}\right) \\
& -\sum_{c \in C}\left(Q_{f c u t} B_{f u}\right)+\sum_{w \in W} \sum_{r \in R} Q_{w r u t} B_{w u} \\
& \left.+\sum_{w \in W} \sum_{k \in K} Q_{w k u t} B_{w u}\right) N c_{f u t} \\
& +\sum_{f \in F}\left(\sum _ { u \in U } \left(\sum _ { t \in T } \left(\left(R F C_{f u t} / R F h_{f u}\right) L_{f}\right.\right.\right. \\
& -\sum_{r \in R}\left(Q_{f r u t} B_{f u}\right)-\sum_{k \in K}\left(Q_{f k u t} B_{f u}\right) \\
& -\sum_{w \in W} \sum_{r \in R} Q_{w r u t} B_{w u} \\
& \left.\left.+\sum_{w \in W} \sum_{k \in K} Q_{w k u t} B_{w u}\right) R N c_{f u t}\right) .
\end{aligned}
$$

\section{Shortage cost (for distributors):}

$$
\begin{aligned}
& \left(\sum _ { c \in C } \left(\sum _ { u \in U } \left(\sum _ { t \in T } \left(\sum_{t-1}^{t} D_{c u t}-\sum_{t-1}^{t} \sum_{d \in D} Q_{d c u t} B_{d u}\right.\right.\right.\right. \\
& \left.\left.\left.\left.-\sum_{t-1}^{t} \sum_{f \in F} Q_{f c u t} B_{f u}-\sum_{t-1}^{t} \sum_{w \in W} Q_{w c u t} B_{w u}\right) S c_{u t}\right)\right)\right) .
\end{aligned}
$$

\section{Purchasing costs:}

$$
\sum_{c \in C} \sum_{a \in A} \sum_{u \in U} \sum_{t \in T} Q_{c a u t} P H_{c u t} B_{c u} .
$$

\section{Disassembly costs:}

$$
\sum_{c \in C} \sum_{a \in A} \sum_{u \in U} \sum_{t \in T} Q_{c a u t} B_{c u} D A c_{a u t} .
$$

\section{Recycling costs:}

$$
\sum_{c \in C} \sum_{a \in A} \sum_{u \in U} \sum_{t \in T} Q_{c a u t} B_{c u} D A c_{a u t} .
$$

\section{Remanufacturing costs:}

$$
\sum_{a \in A} \sum_{f \in F} \sum_{u \in U} \sum_{t \in T} Q_{a f u t} B_{a u} R F c_{f u t} .
$$

\section{Repairing costs:}

$$
\sum_{a \in A} \sum_{r \in R} \sum_{u \in U} \sum_{t \in T} Q_{a r u t} B_{a u} R P c_{a u t} .
$$

Disposal costs:

$$
\sum_{a \in A} \sum_{p \in P} \sum_{u \in U} \sum_{t \in T} Q_{a p u t} B_{a u} P c_{p u t}
$$

\section{Transportation costs:}

$\sum_{t \in T} \sum_{u \in U} \sum_{s \in S} \sum_{f \in F} Q_{s f u t} B_{s u} T c_{u t} D S_{s f}$

$+\sum_{t \in T} \sum_{u \in U} \sum_{f \in F} \sum_{d \in D} Q_{f d u t} B_{f u} T c_{u t} D S_{f d}$

$+\sum_{t \in T} \sum_{u \in U} \sum_{f \in F} \sum_{w \in W} Q_{f w u t} B_{f u} T c_{u t} D S_{f w}$

$+\sum_{t \in T} \sum_{u \in U} \sum_{f \in F} \sum_{c \in C} Q_{f c u t} B_{f u} T c_{u t} D S_{f c}$

$+\sum_{t \in T} \sum_{u \in U} \sum_{f \in F} \sum_{k \in K} Q_{f k u t} B_{f u} T c_{u t} D S_{f k}$

$+\sum \sum \sum \sum Q_{w c u t} B_{w u} T c_{u t} D S_{w c}$

$\sum_{t \in T} \sum_{u \in U} \sum_{w \in W} \sum_{c \in C}$

$+\sum_{t \in T} \sum_{u \in U} \sum_{w \in W} \sum_{k \in K} Q_{w k u t} B_{w u} T c_{u t} D S_{w k}$

$+\sum_{t \in T} \sum_{u \in U} \sum_{d \in D} \sum_{c \in C} Q_{d c u t} B_{d u} T c_{u t} D S_{d c}$

$+\sum_{t \in T} \sum_{u \in U} \sum_{a \in A} \sum_{s \in S} Q_{a s u t} B_{a u} T c_{u t} D S_{a s}$

$+\sum_{t \in T} \sum_{a \in A} \sum_{u \in U} \sum_{f \in F} Q_{a f u t} B_{a u} T c_{u t} D S_{a f}$

$+\sum_{t \in T} \sum_{u \in U} \sum_{a \in A} \sum_{p \in P} Q_{a p u t} B_{a u} T c_{u t} D S_{a p}$

$+\sum_{t \in T}^{t \in T} \sum_{u \in U} \sum_{a \in A} \sum_{r \in R} Q_{a r u t} B_{a u} T c_{u t} D S_{a r}$ $\sum_{t \in T} \sum_{u \in U} \sum_{a \in A} \sum_{r \in R}$

$+\sum_{t \in T} \sum_{u \in U} \sum_{f \in F} \sum_{r \in R} Q_{f r u t} B_{f u} T c_{u t} D S_{f r}$

$+\sum_{t \in T} \sum_{u \in U} \sum_{w \in W} \sum_{r \in R} Q_{w r u t} B_{w u} T c_{u t} D S_{w r}$

$+\sum_{t \in T} \sum_{\in U} \sum_{r \in R} \sum_{k \in K} Q_{r k u t} B_{r u} T c_{u t} D S_{r u k}$

$\sum_{t \in T} \sum_{u \in U} \sum_{r \in R} \sum_{k \in K}$

$+\sum_{t \in T} \sum_{u \in U} \sum_{c \in A} Q_{c a u t} B_{c u} T c_{u t} D S_{c a}$

$+\sum_{t \in T}^{t \in T} \sum_{u \in U} \sum_{w \in W}^{c \in C} \sum_{d \in D}^{c} Q_{w d u t} B_{w u} T c_{u t} D S_{w d}$

\section{Inventory holding costs:}

$$
\begin{array}{rl}
\sum_{w \in W} \sum_{u \in U} \sum_{t \in T} R_{w u t} & W H_{w u t} \\
& +\sum_{d \in D} \sum_{u \in U} \sum_{t \in T} R_{d u t} D H_{d u t} .
\end{array}
$$

3.2. Constraints. Different constraints of the model are presented and explained as follows:

$$
\begin{aligned}
\sum_{s \in S} Q_{s f u t} B_{s u}= & \sum_{d \in D} Q_{f d u t} B_{f u}+\sum_{w \in W} Q_{f w u t} B_{f u} \\
& +\sum_{c \in C} Q_{f c u t} B_{f u}, \\
& \forall t \in T, \forall u \in U, \forall f \in F,
\end{aligned}
$$

$$
\begin{aligned}
\sum_{f \in F} Q_{f w u t} B_{f u}+R_{w u(t-1)} & \\
= & R_{w u t}+\sum_{d \in D} Q_{w d u t} B_{w u} \\
& +\sum_{c \in C} Q_{w c u t} B_{w u}+\sum_{k \in K} Q_{w k u t} B_{w u}, \\
& \forall t \in T, \forall u \in U, \forall w \in W,
\end{aligned}
$$




$$
\begin{gathered}
\sum_{f \in F} Q_{f d u t} B_{f u}+\sum_{w \in W} Q_{w d u t} B_{w u}+R_{d u(t-1)} \\
=R_{d u t}+\sum_{c \in C} Q_{d c u t} B_{d u}, \\
\forall t \in T, \forall u \in U, \forall d \in, D
\end{gathered}
$$$$
\sum_{d \in D} Q_{d c u t} B_{d u}+\sum_{f \in F} Q_{f c u t} B_{f u}+\sum_{w \in W} Q_{w c u t} B_{w u}
$$$$
\leq D_{c u t}+\sum_{1}^{t} D_{c u(t-1)}-\left(\sum_{d \in D} \sum_{1}^{t} Q_{d c u(t-1)} B_{d u}\right.
$$$$
\left.+\sum_{f \in F} \sum_{1}^{t} Q_{f c u(t-1)} B_{f u}+\sum_{w \in W} \sum_{1}^{t} Q_{w c u(t-1)} B_{w u}\right),
$$$$
\forall t \in T, \forall u \in U, \forall c \in C,
$$

$$
\begin{aligned}
& \sum_{a \in A} Q_{c a u t} B_{c u} \\
& \leq\left(\sum_{d \in D} Q_{d c u t} B_{d u}+\sum_{f \in F} Q_{f c u t} B_{f u}\right. \\
&\left.+\sum_{w \in W} Q_{w c u t} B_{w u}\right) R R_{u t}, \\
& \forall t \in T, \forall u \in U, \forall c \in C
\end{aligned}
$$

$$
\begin{gathered}
\sum_{c \in C} Q_{c a u t} B_{c u} \\
=\sum_{s \in S}\left(Q_{a s u t} B_{a u}\right)+\sum_{f \in F}\left(Q_{a f u t} B_{a u}\right) \\
+\sum_{r \in R}\left(Q_{a r u t} B_{a u}\right)+\sum_{p \in P}\left(Q_{a p u t} B_{a u}\right), \\
\forall t \in T, \forall u \in U, \forall a \in A, \\
\sum_{c \in C}\left(Q_{c a u t} B_{c u}\right) R c=\sum_{s \in S}\left(Q_{a s u t} B_{a u}\right), \\
\forall t \in T, \forall u \in U, \forall a \in A, \\
\sum_{c \in C}\left(Q_{c a u t} B_{c u}\right) R m=\sum_{f \in F}\left(Q_{a f u t} B_{a u}\right), \\
\forall t \in T, \forall u \in U, \forall a \in A, \\
\sum_{c \in C}\left(Q_{c a u t} B_{c u}\right) R r=\sum_{r \in R}\left(Q_{a r u t} B_{a u}\right), \\
\forall t \in T, \forall u \in U, \forall a \in A,
\end{gathered}
$$

$$
\begin{gathered}
\sum_{c \in C}\left(Q_{c a u t} B_{c u}\right) R p=\sum_{p \in P}\left(Q_{a p u t} B_{a u}\right), \\
\forall t \in T, \forall u \in U, \forall a \in A
\end{gathered}
$$

$$
\begin{aligned}
& \sum_{a \in A}\left(Q_{a f u t} B_{a u}\right) \\
& =\sum_{r \in R}\left(Q_{f r u t} B_{f u}\right)+\sum_{k \in K}\left(Q_{f k u t} B_{f u}\right) \\
& +\sum_{w \in w} \sum_{k \in K}\left(Q_{w k u t} B_{w u}\right) \\
& +\sum_{w \in w} \sum_{r \in R}\left(Q_{w r u t} B_{w u}\right), \\
& \quad \forall t \in T, \forall u \in U, \forall f \in F,
\end{aligned}
$$

$$
\begin{gathered}
\sum_{a \in A}\left(Q_{a r u t} B_{a u}\right)+\sum_{f \in F}\left(Q_{f r u t} B_{f u}\right) \\
+\sum_{w \in W}\left(Q_{w r u t} B_{w u}\right)=\sum_{k \in K}\left(Q_{r k u t} B_{r u}\right), \\
\forall t \in T, \forall u \in U, \forall r \in R, \\
\sum_{r \in R}\left(Q_{r k u t} B_{r u}\right) \leq D_{k u t}, \\
\forall t \in T, \forall u \in U, \forall k \in K .
\end{gathered}
$$

The constraints (16) to (28) are balanced constraints. Indeed, at each node, all products entering flows per period should be equal to all issuing flows of that node for the same product in the same period. Certainly, for all the entities in the network, these constraints should be set. Therefore, the constraints (16) are balance constraints of manufacturers, the constraints (17) to (21) are for warehouses (17), distributors (18), customers (19), disassembly centers' inputs (20), and disassembly centers output (21), respectively. Again, constraints (22) to (28) are recycling rate constraints (22), remanufacturing rate constraints (23), repairing rate constraints (24), disposal rate constraints (25), manufacturers reverse flows (26), redistributors (27) and, finally second customers balance constraints (28). The sum of all assigning rates via disassembly centers should be equal to one (constraint (62)).

We then have

$$
\sum_{f \in F} Q_{s f u t} B_{s u} \leq S C_{s u t} L_{s}
$$

$\forall t \in T, \forall u \in U, \forall s \in S$, 


$$
\begin{aligned}
& \left(\sum_{d \in D} Q_{f d u t} B_{f u}+\sum_{w \in W} Q_{f w u t} B_{f u}\right. \\
& \left.+\sum_{c \in C} Q_{f c u t} B_{f u}+\sum_{k \in K} Q_{f k u t} B_{f u}\right) F h_{f u} \\
& \leq F C_{f u t} L_{f}, \\
& \forall t \in T, \forall u \in U, \forall f \in F,
\end{aligned}
$$$$
R_{w u t} \leq S C_{w u t} L_{w},
$$$$
\forall t \in T, \forall u \in U, \forall w \in W,
$$

$$
\begin{gathered}
\sum_{f \in F} Q_{f d u t} B_{f u}+\sum_{w \in W} Q_{w d u t} B_{w u}+R_{d u(t-1)} \\
\leq D C_{d u t} L_{d}, \quad \forall t \in T, \forall u \in U, \forall d \in D
\end{gathered}
$$

$$
\begin{aligned}
& \sum_{s \in S} Q_{a s u t} B_{a u}+\sum_{f \in F} Q_{a f u t} B_{a u} \\
& \quad+\sum_{r \in R} Q_{a r u t} B_{a u}+\sum_{p \in P} Q_{a p u t} B_{a u} \\
& \quad \leq A C_{a u t} L_{a}, \quad \forall t \in T, \forall u \in U, \forall a \in A,
\end{aligned}
$$$$
\sum_{k \in K} Q_{r k u t} B_{r u} \leq R C_{r u t} L_{r},
$$$$
\forall t \in T, \forall u \in U, \forall r \in R,
$$

$$
\begin{aligned}
& \sum_{a \in A} Q_{a s u t} B_{a u} \leq S R C_{\text {sut }} L_{s}, \\
& \forall t \in T, \forall u \in U, \forall s \in S,
\end{aligned}
$$

$$
\begin{aligned}
& \sum_{a \in A} Q_{a p u t} B_{a u} \leq P C_{p u t} L_{p}, \\
& \forall t \in T, \forall u \in U, \forall p \in P,
\end{aligned}
$$

$$
\begin{aligned}
\sum_{f \in F} Q_{f w u t} B_{f u} \leq W C_{w u t} L_{w} & \\
& \forall t \in T, \forall u \in U, \forall w \in W .
\end{aligned}
$$

The constraints (29) to (37) are capacity constraints, which control the maximum flows that can enter/issue from each node. The constraint (29) controls all suppliers' output capacity for each product in all periods. The constraints (30) to (37) are for capacity of manufacturers, warehouses, distributors, redistributors, suppliers, disposal centers, and warehouses inputs.

Furthemore,

$$
\begin{aligned}
& L i_{s f} \leq \sum_{u \in U} \sum_{t \in T} Q_{s f u t} \leq M L i_{s f}, \\
& \forall s \in S, \forall f \in F, \\
& L i_{f d} \leq \sum_{\substack{u \in U \\
\sum_{t \in T}}} Q_{f d u t} \leq M L i_{f d}, \\
& \forall f \in F, \forall d \in D,
\end{aligned}
$$

$$
\begin{aligned}
& L i_{f w} \leq \sum_{u \in U} \sum_{t \in T} Q_{f w u t} \leq M L i_{f w}, \\
& \forall f \in F, \forall w \in W
\end{aligned}
$$

$$
\begin{aligned}
& L i_{f c} \leq \sum_{u \in U} \sum_{t \in T} Q_{f c u t} \leq M L i_{f c}, \\
& \forall f \in F, \forall c \in C,
\end{aligned}
$$

$L i_{f k} \leq \sum_{u \in U} \sum_{t \in T} Q_{f k u t} \leq M L i_{f k}$, $\forall f \in F, \forall k \in K$,

$$
L i_{f r} \leq \sum_{u \in U} \sum_{t \in T} Q_{\text {frut }} \leq M L i_{f r},
$$$$
\forall r \in R, \forall f \in F \text {, }
$$

$L i_{w d} \leq \sum_{u \in U} \sum_{t \in T} Q_{w d u t} \leq M L i_{w d}$,

$\forall w \in W, \forall d \in D$,

$L i_{w c} \leq \sum_{u \in U} \sum_{t \in T} Q_{w c u t} \leq M L i_{w c}$, $\forall w \in W, \forall c \in C$,

$L i_{w k} \leq \sum_{u \in U} \sum_{t \in T} Q_{w k u t} \leq M L i_{w k}$, $\forall w \in W, \forall k \in K$,

$L i_{w r} \leq \sum_{u \in U} \sum_{t \in T} Q_{w r u t} \leq M L i_{w r}$, $\forall w \in W, \forall r \in R$,

$$
L i_{d c} \leq \sum_{u \in U} \sum_{t \in T} Q_{d c u t} \leq M L i_{d c},
$$

$\forall d \in D, \forall c \in C$,

$$
L i_{c a} \leq \sum_{u \in U} \sum_{t \in T} Q_{c a u t} \leq M L i_{c a},
$$

$\forall a \in A, \forall c \in C$,

$$
\begin{aligned}
& L i_{a s} \leq \sum_{u \in U} \sum_{t \in T} Q_{a s u t} \leq M L i_{a s}, \\
& \forall s \in S, \forall a \in A,
\end{aligned}
$$




$$
\begin{aligned}
& L i_{a f} \leq \sum_{u \in U} \sum_{t \in T} Q_{a f u t} \leq M L i_{a f}, \\
& \forall f \in F, \forall a \in A, \\
& L i_{a r} \leq \sum_{u \in U} \sum_{t \in T} Q_{a r u t} \leq M L i_{a r}, \\
& \forall r \in R, \forall a \in A, \\
& L i_{a p} \leq \sum_{u \in U} \sum_{t \in T} Q_{a p u t} \leq M L i_{a p}, \\
& \forall p \in P, \forall a \in A, \\
& L i_{r k} \leq \sum_{u \in U} \sum_{t \in T} Q_{r k u t} \leq M L i_{r k}, \\
& \forall k \in K, \forall r \in R .
\end{aligned}
$$

The constraints (38) to (54) manage links between all nodes. As the left-hand sides of the constraints (38) are considered, if there are no flows between a supplier and a manufacturer of all products in all periods, then there should be no link between these two entities. Again, based on the right side of the same constraint, if there is no real link or shipping between these two suppliers and manufacturers, we definitely cannot have any network flows here. These constraints guarantee there are no links between nodes without any actual real flows and no flows between two nodes without any actual link.

We then have

$$
\begin{gathered}
\sum_{s \in S} L_{s} \leq S^{\prime}, \\
\sum_{f \in F} L_{f} \leq F^{\prime}, \\
\sum_{d \in D} L_{d} \leq D^{\prime}, \\
\sum_{w \in W} L_{w} \leq W^{\prime} \\
\sum_{a \in A} L_{a} \leq A^{\prime}, \\
\sum_{r \in R} L_{r} \leq R^{\prime}, \\
\sum_{p \in P} L_{p} \leq P^{\prime} \\
R c+R+R r+R p=1 .
\end{gathered}
$$

The constraints (55) to (61) manage the maximum number of allowable locations. Surely, there are some limitations on the number of activated locations. As a result, these constraints cope with the above-mentioned limitation and do not let the supply chain establish more possible nodes than relative possible limitations.

\section{Solution methodology}

In this section, the proposed two-phase solution methodology is completely explained and discussed. The proposed optimization procedure is debated in detail based on these phases.

4.1. Holistic view of two-phase solution methodology. In order to have a holistic view of the procedure of forecasting and solving the closed-loop supply chain model discussed earlier, all steps are illustrated in Fig. 1.

As can be seen, a two-phase solution methodology is proposed to deal with the forecasting of returns and the network optimization problem. Due to the high uncertainties involved in predicting the amount of return products to the reverse supply chain, an ANFIS methodology is developed and utilized in Phase 1. The amount of the used product (return) is directly related to that of previous demands, the percentage of customer willingness to return the used product, and the incentives provided to the customers. Hence, there is a need to develop a powerful method which could accurately predict the amount of return. The developed ANFIS method can forecast proper return rates for each period to have a logical estimate of the amounts of returns. Finally, at the end of the next phase, we know acceptable forecasting values for return products and, based on these results and other parameters, we can optimize the integrated closed-loop supply chain. At the second stage, the optimization problem is solved and the optimum values of decision variables are assigned. As this problem is a location-allocation one, the main decision variables would be network configuration (network design) and the network flows. Eventually, the proposed method is more compatible with real situations in terms of considering the high uncertainties on the amount of return products, and the results will be more reliable. In the next part, the proposed ANFIS methodology will be explained.

4.2. Proposed ANFIS methodology. ANFIS is an adaptive fuzzy neural based Fuzzy Inference System (FIS). Due to its adaptability nature the membership function parameter can adapt to and change within the learning procedure (Kannan et al., 2013). For more details about the ANFIS architecture and learning rules, one can refer to Jang (1993).

To make a simple ANFIS illustration, we consider an FIS consisting of five layers of adaptive networks, two inputs, and one output, as shown in Fig. 2.

The fuzzy if-then rules can be represented as follows:

$$
\begin{gathered}
\text { If } x \text { is } A_{1} \text { and } y \text { is } B_{1} \text { then } \\
f_{1}=p_{1} x+q_{1} y+r_{1},
\end{gathered}
$$

where $p, r$, and $q$ are linear output parameters. 


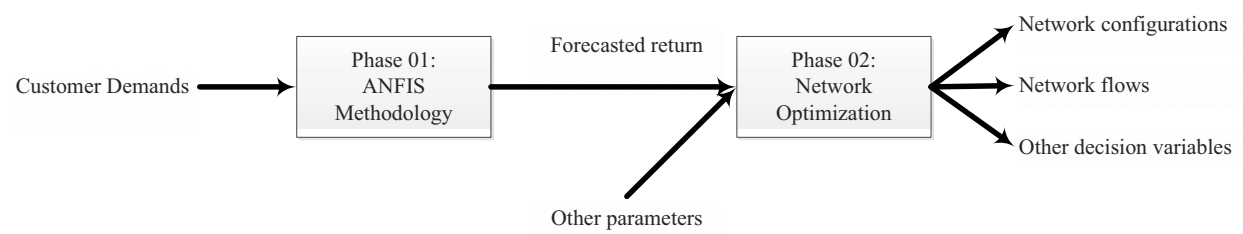

Fig. 1. Proposed two-phase solution methodology.

The detailed descriptions op the five layers are provided below.

Layer 1: The first layer is a fuzzy layer otherwise called a fuzzification layer, in which $x, y$ represent the input of nodes $A$ and $B$. The membership function of $A_{i}$ is denoted by $O_{1, i}$ and is represented by the following equation:

$$
O_{1, i}=\mu A_{i}(x), \quad i=1,2, \ldots, N .
$$

In this paper, we use a triangular membership function.

Layer 2: The second layer is called as a product layer, every node is represented by a circle, which multiplies incoming signals and sends the product out using (Wei, 2011):

$$
O_{2, i}=\omega=\mu A_{i}(x) \mu B_{i}(y), \quad i=1,2, \ldots, N .
$$

Layer 3: This is called a normalized layer and the nodes in this layer are labeled as $N$. The output of this layer is a normalization of the output of Layer 2 (Sivasankaran et al., 2011):

$$
\bar{\omega}_{i}=\frac{\omega_{i}}{\omega_{1}+\omega_{2}+\cdots+\omega_{N}}, \quad i=1,2, \ldots, N .
$$

Layer 4: The fourth layer is called a de-fuzzification layer, where every node $i$ is an adaptive node labeled as a square; each node function is defined as

$$
\begin{aligned}
O_{i}^{4} & =\bar{\omega}_{i} f_{i} \\
& =\bar{\omega}_{i}\left(p_{i} x+q_{i} y+, \ldots,+r_{i}\right), \quad i=1,2, \ldots, N .
\end{aligned}
$$

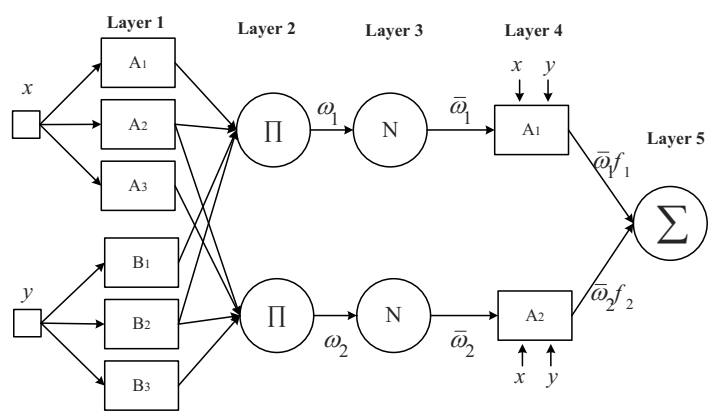

Fig. 2. ANFIS model structure (adopted from Kannan (2013)). where $\bar{\omega}_{i}$ the output of the third layer and $\left\{p_{i}, q_{i}, r_{i}\right\}$ is the parameter set. Linear parameters in this layer are referred to as consequent parameters.

Layer 5: The last layer is a total output layer. A single node in this layer is a circular node, which is labeled as $\sum$, and it computes the overall output of the ANFIS as the summation of all incoming signals (Kannan et al., 2013):

$$
O_{i}^{5}=\text { Overall output }=\sum_{i} \bar{\omega}_{i} f_{i}=\frac{\sum_{i} \omega_{i} f_{i}}{\sum_{i} \omega_{i}}
$$

Consequently, based on the above-mentioned steps, the proposed ANFIS methodology can forecast the return product amount to be able to cope with the uncertainties of this parameter. The evaluation of the proposed two-phase methodology is performed in the next section.

\section{Computational study}

In order to evaluate the proposed two-phase solution methodology, we have to study the performance of the ANFIS forecasting methodology, and then we can solve the design and planning model of closed-loop supply chain. Thus, the proposed solution methodology should also be evaluate in two complete steps: evaluating the forecasting part (ANFIS), and analyzing design and the planning part.

\subsection{Performance evaluation of the proposed ANFIS} forecasting methodology. The proposed model consists of 625 data sets for training and testing purposes. The data related to amount of return products obey a pattern to make the forecasting procedure more consistent with real situations. This pattern is illustrated in Fig. 3 during 25 subperiods (5 main periods). This pattern has sufficient fluctuations and a minor trend in whole periods. Demands will be collected in the next periods based on these values of return rates. For instance, $20 \%$ of total demands of subperiod 1 will be available in the next period as the return product amounts. Thus, we know how much of the current demands will come back to the reverse supply chain network in the next period. Consequently, we will give two types of data: the real data and the forecasting ones. Out of those, 375 data sets were used for the training 
purpose and 250 data sets for testing purpose. In this work, we used triangular membership function for the input and output.

After training the proposed ANFIS model using the input training data set, testing data sets were entered into the model to predict the amounts of return products to the reverse supply chain. The performance capability of the trained model for the proposed model is examined with the help of $R^{2}$, Mean Absolute Deviation (MAD), Mean Absolute Percentage Error (MAPE) and Root Mean Square Error (RMSE). Table 3 shows the performance of the proposed method. It is evident here that the RMSE performance is statistically significant by considering the statistical range studied by Diebold and Mariano (1995). Under the considerations of Table 3, the performance of the proposed ANFIS forecasting methodology is evaluated and it can present acceptable return product amounts in comparison with real data.

5.2. Optimizing the design and planning problem. In order to solve and optimize the design and planning problem of the proposed closed-loop supply chain regarding the results of phase 1 , we construct a closed-loop supply chain network with five units in each entity. Indeed, we will have five numbers of suppliers, five numbers of manufacturers, five numbers of warehouses, etc. for five products in five main-periods. Each main period consists of five sub-periods. Actually, there are 25 sub-periods in this study. This model is coded by the IBM ILOG CPLEX 12.2 optimization software to achieve to the global optimum. All computations are run by a Core 2 Duo $2.26 \mathrm{GHz}$ processor laptop. The parameters are generated by the uniform distribution presented in Table 4. It should be noted that the recycling, remanufacturing, repair, and disposal rates are 0.2, 0.4, 0.3, and 0.1, respectively. It should also be stated that the batch sizes are one and the mutation rate is 0.2. Finally, the proposed network with five units of each entity will construct a

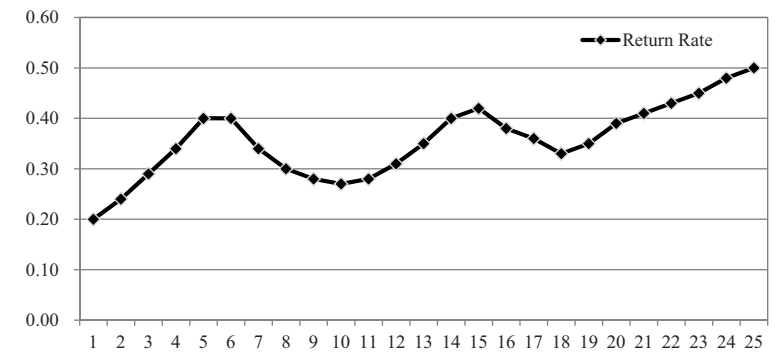

Fig. 3. Return rate pattern for 25 sub-periods.

Table 3. ANFIS predicted amounts of returns.

\begin{tabular}{|c|c|c|c|}
\hline R2 & MAD & MAPE & RMSE \\
\hline \hline 0.972501 & 0.074535 & 0.005213 & 0.074512 \\
\hline
\end{tabular}

network with 11366 decision variables including 460 binary variables and 14482 constraints.

As is evidenced in Table 4, uniform distributions are employed to have different kinds of instances. The results of global objective functions of the model with real return data and the proposed two-phase model (forecasted return data of utilizing an ANFIS) for each of the five main periods are presented in Table 5.

Analyzing Table 5 can lead us to valuable points of the acceptable performance of the proposed two-phase methodology. In Table 5, the results of the five main periods (each consist of five sub-periods) are illustrated.

Table 4. Range of parameters in the computational study (Soleimani et al., 2013).

\begin{tabular}{|c|c|c|}
\hline Row & Parameter & $\begin{array}{l}\text { Uniform distribution } \\
\text { or rate }\end{array}$ \\
\hline 1. & Demands & $0-3000$ \\
\hline 2. & $\begin{array}{l}\text { Second demands } \\
\text { rate }\end{array}$ & $50 \%$ of demand \\
\hline 3. & Prices & $15000-20000$ \\
\hline 4. & $\begin{array}{l}\text { Second products } \\
\text { prices }\end{array}$ & $50 \%$ of price \\
\hline 5. & $\begin{array}{c}\text { Purchasing } \\
\text { costs }\end{array}$ & $10 \%$ of price \\
\hline 6. & $\begin{array}{l}\text { Manufacturers } \\
\text { capacities }\end{array}$ & $6000-14000$ \\
\hline 7. & $\begin{array}{l}\text { Remanufacturers } \\
\text { capacities }\end{array}$ & $\begin{array}{c}50 \% \text { of manufacturer } \\
\text { capacity }\end{array}$ \\
\hline 8. & $\begin{array}{l}\text { Suppliers } \\
\text { capacities }\end{array}$ & $18000-42000$ \\
\hline 9. & $\begin{array}{c}\text { Suppliers recycling } \\
\text { capacities }\end{array}$ & $\begin{array}{l}50 \% \text { of supplier } \\
\text { capacity }\end{array}$ \\
\hline 10. & Recycling costs & $10-100$ \\
\hline 11. & All other reverse costs & $10-100$ \\
\hline 12. & $\begin{array}{c}\text { Others facilities } \\
\text { capacities }\end{array}$ & $6000-14000$ \\
\hline 13. & Material costs & $100-1000$ \\
\hline 14. & Manufacturing costs & $100-1000$ \\
\hline 15. & $\begin{array}{l}\text { All other forward } \\
\text { costs }\end{array}$ & $100-1000$ \\
\hline 16. & Shortage costs & $1000-5000$ \\
\hline 17. & Suppliers fixed costs & $7-10$ million \\
\hline 18. & $\begin{array}{l}\text { Manufacturers fixed } \\
\text { costs } \\
\end{array}$ & 70-150 million \\
\hline 19. & $\begin{array}{l}\text { Distributors fixed } \\
\text { costs }\end{array}$ & $1-2$ million \\
\hline 20. & $\begin{array}{l}\text { warehouses fixed } \\
\text { costs }\end{array}$ & $0.1-1$ million \\
\hline 21. & $\begin{array}{l}\text { Disassemblies fixed } \\
\text { costs }\end{array}$ & $0.1-1$ million \\
\hline 22. & $\begin{array}{l}\text { Redistributors fixed } \\
\text { costs }\end{array}$ & $0.1-1$ million \\
\hline 23. & $\begin{array}{c}\text { Disposal centers fixed } \\
\text { costs }\end{array}$ & $0.1-1$ million \\
\hline 24. & Batch size & 1 \\
\hline
\end{tabular}


Table 5. Comparing results of the proposed-two-phase model and real data (millions).

\begin{tabular}{|c|c|c|c|}
\hline Methodology & Period 01 & Period 02 & Period 03 \\
\hline \hline Real model & 3276.47 & 3161.08 & 3193.69 \\
\hline $\begin{array}{c}\text { Two-phase } \\
\text { model }\end{array}$ & 3275.99 & 3161.72 & 3192.82 \\
\hline $\begin{array}{c}\text { Differences } \\
\text { (millions) }\end{array}$ & 0.48 & -0.64 & 0.87 \\
\hline $\begin{array}{c}\text { Differences } \\
\text { (percentage) }\end{array}$ & $0.01 \%$ & $0.02 \%$ & $0.03 \%$ \\
\hline \hline Methodology & Period 04 & Period 05 & Average \\
\hline \hline Real model & 3059.98 & 3374.19 & 3276.47 \\
\hline $\begin{array}{c}\text { Two-phase } \\
\text { model }\end{array}$ & 3061.69 & 3375.25 & 3275.99 \\
\hline $\begin{array}{c}\text { Differences } \\
\text { (millions) }\end{array}$ & -1.71 & -1.06 & 0.48 \\
\hline $\begin{array}{c}\text { Differences } \\
\text { (percentage) }\end{array}$ & $0.06 \%$ & $0.03 \%$ & $0.01 \%$ \\
\hline
\end{tabular}

The first row is aimed to present the value of the objective function (profit) for real data, and the second row depicts the performance of the proposed two-phase methodology containing ANFIS forecasting data. The results prove excellent behavior of the proposed methodology. The results of the ANFIS are acceptably close to the real data. The average differences between real model with real data and the developed two-phase method with forecasted return data, which are predicted utilizing the ANFIS methodology, are just $0.03 \%$. Considering the fluctuated pattern of return rate illustrated in Fig. 3, this small difference can convince us about the powerful behavior of the ANFIS method as a forecasting methodology and the proposed two-phase methodology.

Another interesting analysis would be evaluating the performances of these two methodologies in network design results. The results of designing the CLSC network are presented in Table 6 . In each period, all the entities of the network can be activated (coded with 1 ) or deactivated (coded with 0). The differences are highlighted in Table 6. The results clarify that, among all 125 decision variables, there are just three different strategic decision variables between the real model and the proposed two-phase ANFIS-based methodology. Again, the network design performance of the developed two-phase method is acceptable.

Consequently, the performance of the proposed two-phase ANFIS-based solution methodology to design and planning a closed-loop supply chain is successfully evaluated. This is so vital based on the importance of estimating reliable data for return products in reverse logistics. Indeed, the only role in the feasibility of reverse logistics belongs to the amount of return data, so this paper attempts to spot light on this main issue.

\section{Conclusion and future research}

In this paper an ANFIS-based integrated forecasting, design, and planning methodology is developed to cope with a multi-period, multi-product, multi-echelon, closed-loop supply chain network. The proposed solution methodology consists of two phases: first, an adaptive network based fuzzy inference system is presented to deal with the uncertainties of the amount of return products and to determine the forecasted return rates; second, the proposed multi-echelon, multi-product, multi-period, closed-loop supply chain design and planning problem is optimized utilizing the forecasted return products of phase 1. The performance of the proposed forecasting method and model is evaluated in 5 main periods and 25 sub-periods for both the phases containing ANFSI and the optimization of the model.

The performance analyses of the ANFIS forecasting methodology prove an acceptable performance of the proposed method based on the reliable values of R2, mean absolute deviation, the mean absolute percentage error, and the root mean square error. On the other hand, the presented instance of the model illustrates an acceptable $0.03 \%$ difference between the two-phase model with forecasted data and the real model. It can also achieve the same 122 design decision variables out of 125 decision variables, which illustrates its consistencies with the model with real data. Finally, the presented two-phase solution methodology could prove its reliability during a computational study. This will help practitioners and managers to cope with design and planning of their closed-loop supply chain regarding real uncertainties of the amounts of return products. Indeed, in such volatile situations, managers need to have reliable design and planning of their CLSC networks based on some reliable forecasts, which we try to propose here.

Some limitations of our paper regard the lack of comparison of similar forecasting methods with the proposed ANFIS and the lack of evaluation through real-data. Therefore, recommendations are for future research are the following: Other forecasting methodologies such as neural networks, regression-based methods, etc. can be studied and compared with the presented method in order to have a fair judgement about their performances. The analysis can be made in larger instances, which are close to real-size cases so it will help to improve the training procedure of the proposed forecasting methodology. Such large instances can prove the applicability of the proposed method. Case study-based research can be applied to the presented two-phase solution methodology to clarify its shortcomings and to improve it. 
Table 6. Results of network design of real data and the two-phase methodology.

\begin{tabular}{|c|c|c|c|c|c|c|c|c|c|c|c|c|c|c|c|c|}
\hline \multirow{2}{*}{ Method } & \multirow{2}{*}{ Period } & \multicolumn{5}{|c|}{ Suppliers } & \multicolumn{5}{|c|}{ Manufacturers } & \multicolumn{5}{|c|}{ Warehouses } \\
\hline & & 1 & 2 & 3 & 4 & 5 & 1 & 2 & 3 & \begin{tabular}{l|l}
4 & \\
\end{tabular} & 5 & \begin{tabular}{l|l}
1 & \\
\end{tabular} & 2 & 3 & 4 & 5 \\
\hline Real & \multirow{2}{*}{1} & 1 & 0 & 0 & 1 & 0 & 0 & 1 & 0 & 1 & 1 & 0 & 1 & 0 & 1 & 0 \\
\hline ANFIS & & 1 & 0 & 0 & 1 & 0 & 0 & 1 & 0 & 1 & 1 & 0 & 1 & 0 & 1 & 0 \\
\hline Real & \multirow{2}{*}{2} & 1 & 0 & 1 & 1 & 0 & 0 & 0 & 1 & 1 & 1 & 0 & 0 & 1 & 1 & 0 \\
\hline ANFIS & & 1 & 0 & 1 & 1 & 0 & 0 & 0 & 1 & 1 & 1 & 0 & 0 & 1 & 1 & 0 \\
\hline Real & \multirow{2}{*}{3} & 1 & 1 & 0 & 1 & 0 & 1 & 0 & 0 & 1 & 1 & 1 & 1 & 0 & 0 & 0 \\
\hline ANFIS & & 1 & 1 & 0 & 1 & 0 & 1 & 0 & 0 & 1 & 1 & 1 & 1 & 0 & 0 & 0 \\
\hline Real & \multirow{2}{*}{4} & 1 & 0 & 0 & 1 & 1 & 0 & 0 & 1 & 1 & 1 & 0 & 0 & 1 & 1 & 0 \\
\hline ANFIS & & 1 & 0 & 0 & 1 & 1 & 0 & 0 & 1 & 1 & 1 & 0 & 0 & 1 & 1 & 0 \\
\hline Real & \multirow{2}{*}{5} & 1 & 0 & 0 & 1 & 0 & 0 & 1 & 0 & 1 & 1 & 0 & 1 & 0 & 1 & 0 \\
\hline ANFIS & & 1 & 0 & 0 & 1 & 0 & 0 & 1 & 0 & 1 & 1 & 0 & 1 & 0 & 1 & 0 \\
\hline \multirow{2}{*}{ Method } & \multirow{2}{*}{ Period } & \multicolumn{5}{|c|}{ "Distributors } & \multicolumn{5}{|c|}{ " Disassembly centers } & \multicolumn{5}{|c|}{ Redistributors } \\
\hline & & $1 \mid$ & 2 & $3 \mid$ & 4 & 5 & 1 & 2 & 3 & 4 & 5 & \begin{tabular}{l|l}
1 & \\
\end{tabular} & 2 & 3 & 4 & 5 \\
\hline Real & \multirow[b]{2}{*}{1} & 0 & 0 & 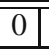 & 1 & 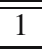 & 1 & 0 & 1 & 1 & 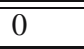 & 1 & 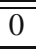 & 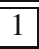 & 1 & $\overline{1} 1$ \\
\hline ANFIS & & 0 & 0 & 0 & 1 & 1 & 1 & 0 & 1 & 1 & 0 & 1 & 0 & 0 & 1 & 1 \\
\hline Real & \multirow{2}{*}{2} & 0 & 0 & 0 & 1 & 1 & 1 & 1 & 0 & 1 & 0 & 1 & 0 & 0 & 1 & 1 \\
\hline ANFIS & & 0 & 0 & 0 & 1 & 1 & 1 & 1 & 0 & 1 & 0 & 1 & 0 & 0 & 1 & 1 \\
\hline Real & \multirow{2}{*}{3} & 1 & 0 & 0 & 0 & 1 & 1 & 1 & 0 & 1 & 0 & 1 & 0 & 0 & 1 & 1 \\
\hline ANFIS & & 1 & 0 & 0 & 0 & 1 & 1 & 1 & 0 & 1 & 0 & 1 & 0 & 0 & 1 & 1 \\
\hline Real & \multirow{2}{*}{4} & 0 & 0 & 0 & 1 & 1 & 1 & 0 & 1 & 1 & 0 & 1 & 0 & 1 & 0 & 1 \\
\hline ANFIS & & 0 & 0 & 0 & 1 & 1 & 1 & 0 & 1 & 1 & 0 & 1 & 0 & 1 & 1 & 1 \\
\hline Real & \multirow{2}{*}{5} & 0 & 0 & 0 & 1 & 1 & 1 & 1 & 1 & 1 & 0 & 1 & 0 & 1 & 1 & 1 \\
\hline ANFIS & & 0 & 0 & 0 & 1 & 1 & 1 & 0 & 1 & 1 & 0 & 1 & 0 & 1 & 1 & 1 \\
\hline \multirow{2}{*}{ Method } & \multirow{2}{*}{ Period } & \multicolumn{5}{|c|}{ " Disposal centers } & & & & & & & & & & \\
\hline & & \begin{tabular}{l|l}
1 & \\
\end{tabular} & $2 \mid$ & \begin{tabular}{l|l}
3 & \\
\end{tabular} & \begin{tabular}{l|l}
4 \\
\end{tabular} & 5 & & & & & & & & & & \\
\hline Real & & 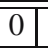 & 0 & 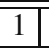 & 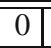 & 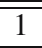 & & & & & & & & & & \\
\hline ANFIS & 1 & 0 & 0 & 1 & 0 & 1 & & & & & & & & & & \\
\hline Real & & 0 & 0 & 1 & 0 & 1 & & & & & & & & & & \\
\hline ANFIS & 2 & 0 & 0 & 1 & 0 & 1 & & & & & & & & & & \\
\hline Real & & 0 & 0 & 1 & 0 & 1 & & & & & & & & & & \\
\hline ANFIS & 3 & 0 & 0 & 1 & 0 & 1 & & & & & & & & & & \\
\hline Real & & 0 & 0 & 1 & 0 & 1 & & & & & & & & & & \\
\hline ANFIS & 4 & 0 & 0 & 1 & 0 & 1 & & & & & & & & & & \\
\hline Real & & 0 & 0 & 1 & 0 & 1 & & & & & & & & & & \\
\hline ANFIS & 5 & 0 & 0 & 1 & 0 & 1 & & & & & & & & & & \\
\hline
\end{tabular}

\section{References}

Brdyś, M.A., Borowa, A., Idźkowiak, P. and Brdyś, M.T. (2009). Adaptive prediction of stock exchange indices by state space wavelet networks, International Journal of Applied Mathematics and Computer Science 19(2): 337-348, DOI: 10.2478/v10006-009-0029-z.

Chang, F.-J. and Chang, Y.-T. (2006). Adaptive neuro-fuzzy inference system for prediction of water level in reservoir, Advances in Water Resources 29(1): 1-10.

Chen, S.-H., Lin, Y.-H., Chang, L.-C. and Chang, F.-J. (2006). The strategy of building a flood forecast model by neuro-fuzzy network, Hydrological Processes 20(7): 1525-1540.

Chittamvanich, S. and Ryan, S.M. (2011). Using forecasted information from early returns of used products to set remanufacturing capacity, Iowa State University, Ames, IA.
Diebold, F.X. and Mariano, R.S. (1995). Comparing predictive accuracy, Journal of Business \& Economic Statistics 13(3): 253-263.

Efendigil, T., Önüt, S. and Kahraman, C. (2009). A decision support system for demand forecasting with artificial neural networks and neuro-fuzzy models: A comparative analysis, Expert Systems with Applications 36(3): 6697-6707.

Georgiadis, P. (2013). An integrated system dynamics model for strategic capacity planning in closed-loop recycling networks: A dynamic analysis for the paper industry, Simulation Modelling Practice and Theory 32(1): 116-137.

Guide, V.D.R. and Van Wassenhove, L.N. (2001). Managing product returns for remanufacturing, Production and $\mathrm{OP}$ erations Management 10(2): 142-155.

Jang, J.-S. (1993). ANFIS: Adaptive-network-based fuzzy inference system, IEEE Transactions on Systems, Man and 
Cybernetics 23(3): 665-685.

Jun Li, R. and Xiong, Z.-B. (2005). Forecasting stock market with fuzzy neural networks, Proceedings of the 2005 International Conference on Machine Learning and Cybernetics, 2005, Guangzhou, China, Vol. 6, pp. 3475-3479.

Kannan, D., Jafarian, A., Khamene, H. and Olfat, L. (2013). Competitive performance improvement by operational budget allocation using ANFIS and fuzzy quality function deployment: A case study, International Journal of Advanced Manufacturing Technology 68(1-4): 849-862.

Krarup, J. and Pruzan, P.M. (1983). The simple plant location problem: Survey and synthesis, European Journal of $\mathrm{Op}$ erational Research 12(1): 36-81.

Liao, H.P., Su, J.P. and Wu, H. (2001). An application of ANFIS to modeling of a forecasting system for the demand of teacher human resources, Journal of Education and Psychology 24(1): 1-17.

Marx-Gomez, J., Rautenstrauch, C., Nürnberger, A. and Kruse, R. (2002). Neuro-fuzzy approach to forecast returns of scrapped products to recycling and remanufacturing, Knowledge-Based Systems 15(12): 119-128.

Ozkr, V. and Balgil, H. (2013). Multi-objective optimization of closed-loop supply chains in uncertain environment, Journal of Cleaner Production 41(0): 114-125.

Schrijver, A. (2004). Combinatorial Optimization: Polyhedra and Efficiency (Algorithms and Combinatorics), Springer, Berlin.

Sfetsos, A. (2000). A comparison of various forecasting techniques applied to mean hourly wind speed time series, Renewable Energy 21(1): 23-35.

Sivasankaran, S., Sivaprasad, K., Narayanasamy, R. and Iyer, V.K. (2011). Evaluation of compaction equations and prediction using adaptive neuro-fuzzy inference system on compressibility behavior of AA 6061 100- x- wt. $\% \mathrm{~T}_{i} \mathrm{O} 2$ nanocomposites prepared by mechanical alloying, Powder Technology 209(1-3): 124-137.

Soleimani, H., Seyyed-Esfahani, M. and Kannan, G. (2014). Incorporating risk measures in closed-loop supply chain network design, International Journal of Production Research 52(6): 1843-1867.

Soleimani, H., Seyyed-Esfahani, M. and Shirazi, M. (2013). Designing and planning a multi-echelon multi-period multi-product closed-loop supply chain utilizing genetic algorithm, International Journal of Advanced Manufacturing Technology 68(1-4): 917-931.

Srivastava, S.K. (2006). Managing product returns for reverse logistics, International Journal of Physical Distribution and Logistics Management 36(7): 524-546.

Sumi, S.M., Zaman, M.F. and Hirose, H. (2012). A rainfall forecasting method using machine learning models and its application to the Fukuoka city case, International Journal of Applied Mathematics and Computer Science 22(4): 841-854, DOI: 10.2478/v10006-012-0062-1.

Temur, G. and Bolat, B. (2012). Reverse logistics network design integrated with product return forecasting approach, 17th International Working Seminar on Production Economics, Innsbruck, Austria, pp. 483-497.
Toktay, B., van der Laan, E.A. and de Brito, M.P. (2003). Managing product returns: The role of forecasting, ERIM Report ERS-2003-023-LIS, Erasmus University Rotterdam, Rotterdam.

Wei, L.-Y. (2011). A fusion ANFIS model for forecasting EPS of leading industries in Taiwan, 2011 International Conference on Machine Learning and Cybernetics (ICMLC), Singapore, Vol. 1, pp. 1-4.

Xu, X. and Fan, T. (2009). Forecast for the amount of returned products based on wave function, 2009 International Conference on Information Management, Innovation Management and Industrial Engineering, Xi'an, China, Vol. 2, pp. 324-327.

Yun, Z., Quan, Z., Caixin, S., Shaolan, L., Yuming, L. and Yang, S. (2008). RBF neural network and ANFIS-based short-term load forecasting approach in real-time price environment, IEEE Transactions on Power Systems 23(3): 853-858.

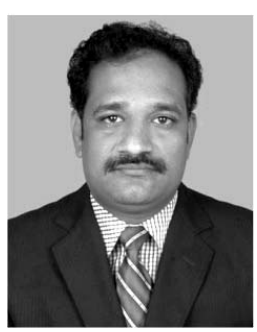

D. Thresh Kumar is the head of a department and an associate professor of mechanical engineering in the P.T.R College of Engineering and Technology, India. He obtained the M.Sc. degree in manufacturing engineering and is currently pursuing his Ph.D in supply chain management at Anna University, Chennai, India. He has published about five papers in journals and conferences.

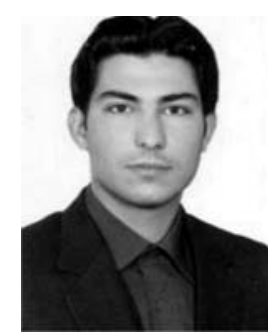

Hamed Soleimani is an assistant professor of industrial engineering at Islamic Azad University (IAU), Qazvin Branch, Iran. He received his Ph.D. from the Amirkabir University of Technology (Tehran Polytechnique) in 2013. He has published various papers in leading journals. $\mathrm{He}$ is also a reviewer of learned journals. His fields of research are supply chain management, stochastic optimization, and metaheuristic algorithms.

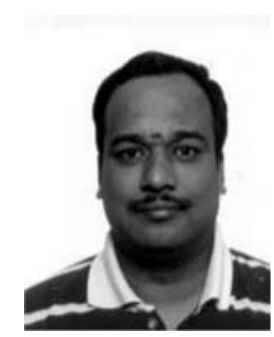

Govindan Kannan is an associate professor of operations and supply chain management in the Department of Business and Economics, University of Southern Denmark. His research interests include logistics, supply chain management, green and sustainable supply chain management, reverse logistics and maritime logistics. He has published more than 80 papers in refereed international journals and over 70 papers in conferences. His publications have appeared in leading journals. He is the editor-in-chief of the International Journal of Advanced Operations Management and the International Journal of Business Performance and Supply Chain Modelling. He is an editorial board member of Resources Conservation and Recycling and Transportation Research, Part E.

Received: 9 August 2013

Revised: 4 November 2013

Re-revised: 21 February 2014 